\title{
Gwên am Byth: a programme introduced to improve the oral health of older people living in care homes in Wales - from anecdote, through policy into action
}

\author{
Elisabeth P. Howells, ${ }^{1}$ Rosalyn Davies, ${ }^{2}$ Vicki Jones ${ }^{3}$ and Maria Z. Morgan ${ }^{\star 4}$
}

\section{Key points}

Older people living in care homes may require day-to-day support with tasks such as oral hygiene; therefore, care home staff require training to safely support residents with effective and appropriate mouth care.
A Welsh Government-funded programme (Gwên am Byth) is described which ensures a consistent approach across Wales with the aim to improve the oral health of older people living in care homes.
Includes practical pointers for those who want to secure resources for vulnerable older people living in care homes and turn policy into action.

\begin{abstract}
Introduction and context This paper describes how research and evidence influenced Welsh Government policy to fund a programme (Gwên am Byth - A Lasting Smile) with the aim of improving the oral health of older people living in care homes. It describes how collaborative multi-agency working supported development and delivery of the programme. The context was policy in Wales. This included the Welsh Government response to the public inquiry into Mid Staffordshire NHS Foundation Trust, the report into care homes by the Older People's Commissioner for Wales, and the Welsh Government Health and Care Standards for Wales which include a standard relating to oral health. The aim was to introduce a programme, Gwên am Byth, to support 'oral hygiene and mouth care for older people living in care homes through the development of a consistent all-Wales approach'; this aligns with contemporaneous NICE guidelines.
\end{abstract}

Materials and methods Recurrent Welsh Government funding was identified to support a community dental service (CDS) led programme (Gwên am Byth). A multi-professional team led the development and testing of materials and resources to support the programme, underpin training for care home staff, and allow them to assess and provide safe mouth care for residents. A Welsh Health Circular was published to ensure a consistent all-Wales approach

Results New staff have been employed in all health boards, and an assessment tool has been developed and is in the final stages of validation. All Wales resources have been published for induction, training and education, and to support care home staff. Evidence-based care plans have been produced which link to individual residents' risks and needs. There is close working with other health and social care professionals. By March 2019, half of all care homes were participating in the programme to a greater or lesser extent. Over 5,000 health and care staff had been trained, and over 5,600 residents had been assessed and supported with delivery of an individual mouth care plan. There has been positive feedback from care home staff, residents, carers and CDS staff, although barriers to delivery remain.

Discussion This paper describes programme delivery in the four years since Gwên am Byth began. The drivers for change are described and the need to influence Welsh Government policy decisions when funding was available. The authors discuss issues which can impact on the pace of change, and ways in which health and care staff can effectively work together to implement improvements.

Conclusions Starting with a blank page, a national programme has been established with the aim of improving the oral health of older people living in care homes in Wales. The paper describes the lessons learnt in implementing the programme and notes that Welsh Government has recognised the value of Gwên am Byth by committing to double the recurrent programme funding.

'Deputy CDO for Wales (now retired), UK; ${ }^{2}$ Senior Improvement Manager, Improvement Cymru, Public Health Wales, UK; ${ }^{3}$ Consultant in Special Care Dentistry, CDS Clinical Director Aneurin Bevan, University Health Board, UK; ${ }^{4}$ Senior Lecturer, Dental Public Health, Cardiff University School of Dentistry \& Honorary Public Health Specialist (Dental), Public Health Wales, UK.

*Correspondence to: Maria Morgan

Email address: morganmz@cardiff.ac.uk

Refereed Paper.

Accepted 10 June 2020

https://doi.org/10.1038/s41415-020-2400-2

\section{Introduction}

Good oral health is important for older people living in care homes - their general health, nutritional intake ${ }^{1,2,3,4}$ and wellbeing. ${ }^{5}$ The UK population is ageing; there are approximately 1.6 million people aged 85 and over - this age group is the fastest growing and set to double to 3.2 million by mid-2041 and treble by $2066 .^{6}$ Approximately 25\% of those aged 85 and over are living in care homes (400,000/1.6 million). ${ }^{7}$

A greater proportion of older people are likely to retain their teeth compared with earlier cohorts. In 1968, 37\% of adults in Wales were edentulous compared with $10 \%$ in $2009,{ }^{8}$ which has implications for the delivery of prevention and dental care to this population.

Based on data published by the Care and Social Services Inspectorate Wales (now CIW or Care Inspectorate Wales) (September 2014), ${ }^{9}$ there are 
circa 23,000 older people resident in care homes in Wales. Many residents have poor or inadequate oral health when they move to their care home, which may be the result of deteriorating health and mobility during the preceding years. On average, older people spend approximately two years living in a care home ${ }^{10}$ and they are some of our most vulnerable citizens. The 2017 Wales market analysis of care homes for older people (draft findings for discussion) documented that 'as we are supporting more people in the community people entering care homes are more frail both mentally and physically than would have been the case years ago. ${ }^{11}$ Many residents have complex needs, requiring day-today support with tasks that most of us take for granted - such as brushing teeth ${ }^{9}$. Up to $70 \%$ of people in care homes have cognitive impairment and increasing numbers have dysphagia or require nutritional supplements. ${ }^{12}$

Effective oral hygiene helps to maintain an individual's wellbeing and dignity, and contributes to quality of life. Good oral health can be promoted by effective daily mouth care supported as necessary by well-trained care home staff.

This paper describes how research and evidence influenced Welsh Government policy to fund a programme (Gwên am Byth - A Lasting Smile) to improve the oral health of older people living in care homes. It describes how collaborative multi-agency working supported development and delivery of the programme, and the recognition that we may need more than the evidence base to exploit opportunities for funding and innovation. In this context, 'care home' encompasses both nursing and residential homes for older people - including people living with dementia.

\section{Key aim}

The aim as stated in the Welsh Health Circular was to introduce a programme, Gwên Am Byth, to support 'oral hygiene and mouth care for older people living in care homes through the development of a consistent all-Wales approach'; 9 this aligns with contemporaneous NICE guidelines. ${ }^{13}$

Surveys in Wales highlight that mouth care for older residents in care homes is seldom optimal. ${ }^{2,3,4,5}$ Residents have differing needs for mouth care and may be:

- Wholly self-caring

- Mostly self-caring but need to be reminded and encouraged to clean their teeth and mouth
- In need of some hands-on support; for example, to prepare toothbrush and paste before brushing their own teeth and mouth

- Dependent on care home staff for all mouth care.

\section{Context}

Informal and formal evidence acted as a catalyst and built momentum to support change.

\section{Informal evidence and drivers for change}

From the late 1980s, community dental service (CDS) and special care dentistry clinicians expressed concern about poor oral hygiene and oral health for older people living in some care homes in Wales.

At the time, the Care and Social Services Inspectorate Wales 'National Minimum Standards' for care homes for older people required care homes to carry out a care needs assessment for every resident, including oral health. This was reinforced by the requirements of the Social Services and Wellbeing (Wales) Act $2014 .{ }^{14}$ Some nurses and care home staff recognised their duty of care for mouth care but noted they lacked the skills, resources and training to support older people in their care.

Specialist societies, such as the British Society of Gerodontology and Age Cymru, also raised concerns about the oral health of older people living in care homes and the number of staff available to provide training in mouth care to carers in care homes.

In 2013, the Welsh Government response to Delivering safe care, compassionate care learning for Wales from the report of the Mid Staffordshire NHS Foundation Trust Public Inquiry ${ }^{15}$ emphasised the importance of 'providing care which is dignified, safe, effective and compassionate and meets individual need.'

It went on to identify that 'how we measure achievement against standards needs to be carefully balanced to ensure we do not risk stifling innovation and continuous quality improvement.'

In the 2014 report A place to call home?,16 the Older People's Commissioner for Wales recognised the importance of oral hygiene and supported the need for timely and appropriate dental care for older people in care homes throughout Wales.

In 2015. the Welsh Government published the 'Health and Care Standards for Wales.' ${ }^{17}$ Standard 4.1 notes the requirement that 'people are supported to maintain a clean, healthy, comfortable mouth and pain-free teeth and gums, enabling them to function as normal (including eating and speaking) and prevent related problems'. The standards provide a foundation for dignified and safe healthcare in Wales.

At the time, the CDS in Wales provided some innovative services in care homes, including oral health improvement activity and different approaches to oral health risk assessment. In some health boards, the CDS provided dental services to care homes while others offered shared care with the general dental service (GDS). There was variation in the extent and nature of GDS involvement and in 'joined up' working across the services.

These different approaches offered a rich environment to share learning and best practice, and helped to influence the design of Gwên am Byth. With their permission, we drew on learning from the Caring for Smiles programme ${ }^{18}$ launched in Scotland in 2013, as Scotland's national oral health promotion, training and support programme for staff in care homes. There were two specific learning points from the programme in Scotland. Firstly, the requirement for a recognisable 'brand' to reinforce the programme as being country-wide and relevant to all care homes for older people. As a result, Wales adopted Gwen am Byth as the programme name. Secondly, the need for a comprehensive manual to be available in all care homes to support and reinforce the training provided to staff, and to be a source of day-today guidance and information on effective mouth care for residents.

\section{Formal evidence (in Wales)}

Research in Wales showed an absence of systems to:

- Assess oral health status on admission to the care home

- Assess need for dental treatment on admission to the care home

- Manage chronic dental disease

- Help residents access dental care across the principality. ${ }^{1}$

Compared with older adults living in their own homes, care home residents were:

- Less likely to brush teeth/dentures twice a day (37\% vs 63\%)

- Have more teeth with active decay $(3.1 \text { vs } 0.9)^{2}$

- Be unable to undertake oral self-care. ${ }^{3}$

In a recent qualitative survey, one resident said: 'I want to die with some [teeth] in my mouth', and had negotiated with her carers to 
have her dentures cleaned twice a week and keep them in her mouth at night for the rest of the week. ${ }^{19}$

These findings had important implications in the development of Gwên am Byth.

\section{Materials and methods}

\section{Policy decisions}

In 2014, the then Chief Dental Officer (CDO) for Wales identified recurrent Welsh Government funding for programmes to improve healthcare, which led to the development of Gwên am Byth. The Deputy $\mathrm{CDO}$ who had previously worked in the CDS and care homes saw an opportunity to make a difference.

\section{Translating policy into action}

The total annual recurrent funding of $£ 249,750$ was shared across the CDSs in the seven health boards in Wales, reflecting the number of care homes within each area. ${ }^{9}$

Health boards were encouraged to collaborate to make best use of resources and achieve economies of scale. Most health boards used their funding to employ a CDS dental registrant to support programme delivery. These new employees were dental care professionals who formed the core of the team delivering 'Gwên am Byth' in line with the principles of prudent healthcare.

\section{A pragmatic approach to engaging care homes and starting to deliver}

There are approximately 650 care homes for older people in Wales. A pragmatic approach was taken to engage the homes, with the Welsh Government expecting the CDS to use the allWales National Improvement methodologies. As a general rule, this means to 'start small' and spread the work step by step. The programme is tested and developed and, when all parties agree, it is consistently embedded as capacity allows.

\section{The intervention}

The CDS, Welsh Government and Public Health Wales worked collaboratively with other healthcare professionals and care home staff to develop, test and implement the programme. Three areas that needed to be developed and embedded in practice were:

1. Care home staff are trained in mouth care (including at induction) and the home keeps a register of training; the format of the training initially is classroom-based, although chairside/bedside support can be provided as required for individual carers/residents. Originally, classroom sessions were planned to last either a morning or afternoon, but CDS teams have had to be flexible with timing at the request of care home managers

2. An oral assessment is carried out which leads to an individual care plan

3. The care plan is delivered and documented.

Other elements of the programme helped to ensure:

- An up-to-date mouth care policy is in place in each care home

- Residents have appropriate mouth care resources for their care plan

- Care home staff can identify local dental services for their residents and refer as appropriate

- Residents (and relatives) are asked for feedback on mouth care.

\section{Care home staff are trained in mouth care}

The training programme was developed in partnership with care homes, consultants in dental public health, and specialists and consultants in special care dentistry in the CDS to ensure it was informed by the evidence base. Training is delivered by Gwên am Byth teams using a consistent all-Wales approach, while acknowledging it may be necessary to tailor to local requirements; for example, in areas where the first language is Welsh.

Experience from previous programmes and elsewhere in the UK shows it is almost impossible to train everybody and keep up with staff turnover and shift working. Therefore, a 'train the trainers' approach was employed. Generic training is delivered to all staff with additional training for 'champions', who then provide in-house induction for new staff. Training is supported by all-Wales resources. ${ }^{20}$

\section{Mouth care assessment tool}

The mouth care assessment tool was developed, using a series of 'plan, do, study, act' (PDSA) cycles which were followed by a process of formal validation. This mouth care assessment is used by trained care home staff who are not GDC registrants; it is not a dental examination and this was confirmed with the GDC.

During the PDSA cycles, care home staff suggested a number of changes to the tool. It must:

- Have a person-centred approach - start with the whole person, not in the mouth

- Be straightforward to use, with unambiguous language

- Avoid meaningless numerical values to describe the severity of the condition of the mouth where it is not amenable to improvement by care home staff (for example, a painless retained decayed root)

- Avoid double barrelling - that is, questions that touch upon more than one issue, but only allow for one answer

- Be done by visual means, or by asking the resident when they have the capacity to respond

- Avoid subjective responses which rely on individual interpretation.

The assessment (Fig. 1) identifies risk factors and problems that need to be referred to the dental team. Ideally, the first assessment should be done within seven days of the resident coming to live in the home, with subsequent assessments carried out monthly in line with the care home assessment policy. Assessment must be done by a suitably trained and qualified care home staff member.

Care homes increasingly use electronic systems for assessments and there is a need to develop the mouth care assessment to fit with a range of software systems.

\section{The care plan}

Unless the assessment leads to a care plan, it is of limited value. The care plan is based on the results of the assessment and the resident's individual needs and capacity. The plan can be delivered by a suitably trained healthcare support worker.

\section{Fig. 1 Selected section: mouth care assessment too ${ }^{20}$}

Part 1: Pre-assessment information

Record if the resident has capacity to consent to a mouthcare assessment.

Residents may have a fluctuating capacity or no capacity and when first asked they may

refuse. If this is the case ask again at another time of the day or the next day.

\begin{tabular}{|l|l|l|l|l|}
\hline $\begin{array}{l}\text { Part 1: Pre-assessment } \\
\text { information }\end{array}$ & Low risk & Medium risk & High risk & $\begin{array}{l}\text { Record the highest risk (L, M or H) } \\
\text { to inform the mouthcare plan }\end{array}$ \\
\hline Consent & $\begin{array}{l}\text { Has capacity to } \\
\text { consent }\end{array}$ & $\begin{array}{l}\text { Capacity } \\
\text { fluctuates }\end{array}$ & $\begin{array}{l}\text { No capacity to } \\
\text { consent }\end{array}$ & Has capacity to consent \\
\hline
\end{tabular}


Staff working in the care home take ownership of the programme and are responsible for ensuring the care plan is delivered. CDS and other dental teams are there to facilitate and support staff to provide care for residents who are dependent on carers for mouth care.

The care plan is dynamic. When subsequent assessments identify changed needs, then the care plan changes accordingly; for example, a resident who develops a compromised swallow and so needs a greater level of support.

Residents need appropriate oral hygiene supplies; these will normally be provided by the resident/family, but sometimes by the care home. Care home staff must adhere to the Wales ban on use of foam swabs for mouth care; ${ }^{21}$ the use of lemon and glycerine swabs is strongly discouraged. When indicated, highfluoride toothpaste may be prescribed by a dentist.

\section{Access to services}

Supported by the health board, care homes should be aware of local dental care services for their residents, ensuring access for both routine and urgent care.

Health boards have a responsibility to ensure dental care is available; this may include shared care or domiciliary services. This will be determined by local arrangements, service capacity and factors such as the complex needs of care home residents.

\section{Governance and oversight}

The programme is guided by a multiorganisation National Advisory Group which acts as a central source of strategic direction for programme delivery, monitoring and evaluation.

Local Implementation Groups (LIGs) plan delivery in each health board and ensure that local stakeholders can contribute effectively. ${ }^{9}$

\section{Results}

Having secured funding, the programme was developed and established, with collaborative working across a range of organisations to ensure a consistent approach. New staff have been employed in all health boards, and an assessment tool has been developed and is in the final stages of validation by Cardiff University and Public Health Wales. All Wales resources have been published for induction, training and education, and to support care home staff. Evidence-based care plans have been

\section{Fig. 2 Care homes}

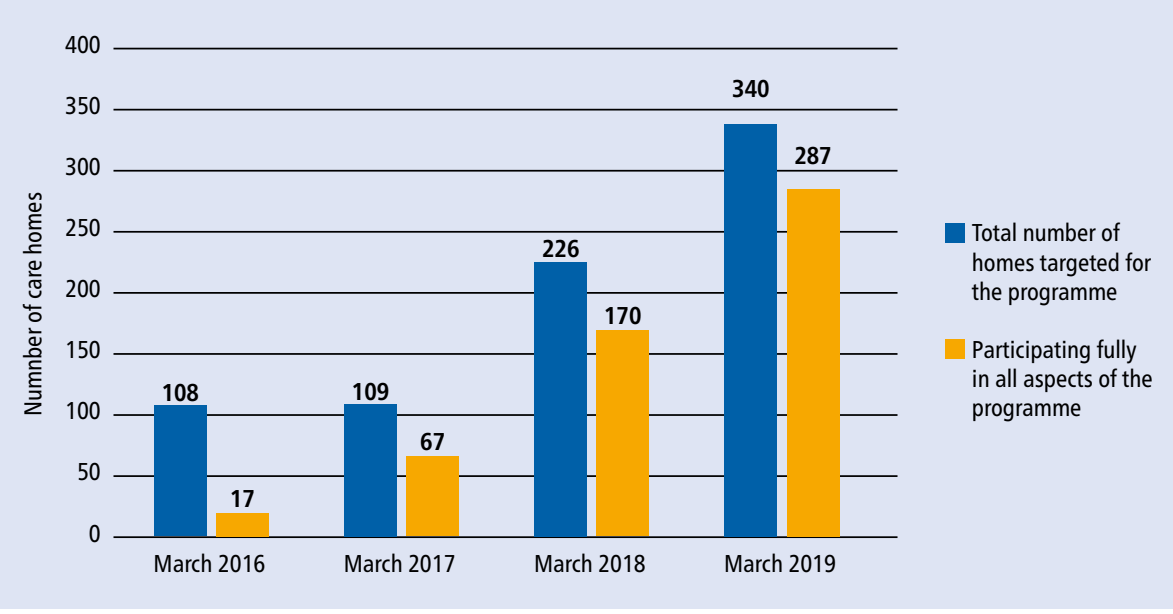

Table 1 of the 340 targeted homes (out of 650 across Wales)

\begin{tabular}{l|l|l|l|l}
\hline Characteristic & $\mathbf{2 0 1 6}$ & $\mathbf{2 0 1 7}$ & $\mathbf{2 0 1 8}$ & $\mathbf{2 0 1 9}$ \\
\hline Participating fully & 17 & 67 & 170 & 287 \\
\hline Participating in part & 86 & 43 & 55 & 33 \\
\hline Decided not to continue & 0 & 1 & 3 & 12 \\
\hline Up-to-date mouth care policy & 92 & 87 & 208 & 288 \\
\hline Can identify their local dental services & 92 & 121 & 210 & 282 \\
\hline $\begin{array}{l}\text { Number of training sessions given to care home } \\
\text { staff by the dental team }\end{array}$ & 0 & 290 & 489 & 524 \\
\hline Oral health champions trained by the CDS & 50 & 209 & 487 & 780 \\
\hline
\end{tabular}

produced which link to individual residents' risks and needs, and opportunities taken to liaise with family and other carers. There is close working with other health and social care professionals (for example, dietitians and contract monitoring teams) and liaison with Care Inspectorate Wales, the successor of Care and Social Services Inspectorate Wales.

Wales has shared good practice with a similar programme in England (Mouth Care Matters) and learnt from them - for example, practical ways to deal with tenacious secretions in the mouth. Local study events have been held at which care home staff have presented alongside dental and health professionals.

Since 2015, there has been a steady rise in the number of homes engaged in the programme and care home staff trained. By March 2019, half of all care homes were participating (Fig. 2 , Table 1) and over 5,000 health and care staff had been trained (Fig. 3). Over 5,600 residents were assessed and supported with delivery of an individual mouth care plan (Fig. 4, Table 2).

There has been positive feedback from care home staff, residents, carers and CDS staff. A resident commented how thrilled she was with the provision of mouth care at her care home: 'Before I came here I never took my dentures out at all but since I have been here they are taken out every day and cleaned and popped into a pot over night. My grandchildren now visit me and sit on my lap and tell me my mouth doesn't smell anymore.'

Gwên am Byth is now an integral part of the wider Care Home Cymru programme, which is funded by Welsh Government and delivered by Improvement Cymru/Public Health Wales. This integration has benefited both programmes through shared learning and experience.

There have been positive impacts on care home staff who are starting to appropriately refer residents to the dental team rather than a general medical practitioner, making better product choices (for example, size of toothbrush) and changing attitudes to their own and their resident's oral hygiene.

As with other healthcare interventions, it can be a challenge to measure outcomes. To date, the focus has been on: assessing compliance with process and standards (as happens with other quality improvement programmes); and 
identifying examples of good practice, and evaluation of training and feedback from care home staff, residents and carers, as well as teams delivering the programme or working in care homes. The programme has adopted proxy measures to assess outcomes. Gwên am Byth is making a difference. It can be difficult to measure oral hygiene status of care home residents who live with dementia and who cannot readily consent to participate in an evaluation, which includes oral examinations to assess change before and after implementing the programme.

Early in the programme, Gwên am Byth teams identified barriers to delivery, including:

- Shift working, staff sickness, high rates of staff turnover and language

- A belief that the process will be onerous or used as a performance management tool

- Care home staff describe having insufficient time to carry out care for residents with behaviour that affects provision of effective mouth care

- Care home staff may not recognise the importance of collecting data; for example, training records.

CDS teams have worked with care home staff, residents, LIGs, nurse leads and Care Inspectorate Wales to identify ways to overcome these barriers.

\section{Discussion}

This paper describes programme delivery in the four years since Gwên am Byth began. However, the overall journey 'from anecdote through policy into action' has taken more than 20 years. We have described the drivers for change, but these had to be conveyed to Welsh Government to influence policy decisions at a time when funding was available.

Change and improvement take time.It has been stated that it takes an average of 17 years for research evidence to reach clinical practice. $^{22}$

A report by The King's Fund noted that, for healthcare, 'in the face of unprecedented financial and service pressures, transformational change is urgently needed (Murray et al. 2018). But [...] it can take many years, sometimes decades, to achieve. ${ }^{23}$

Effective engagement between the CDS, care home representatives and Welsh Government helped to facilitate change, as well as the presence of a national programme (1000 Lives Service Improvement) which was already making improvements in NHS Wales.

\section{Fig. 3 Care home personnel}

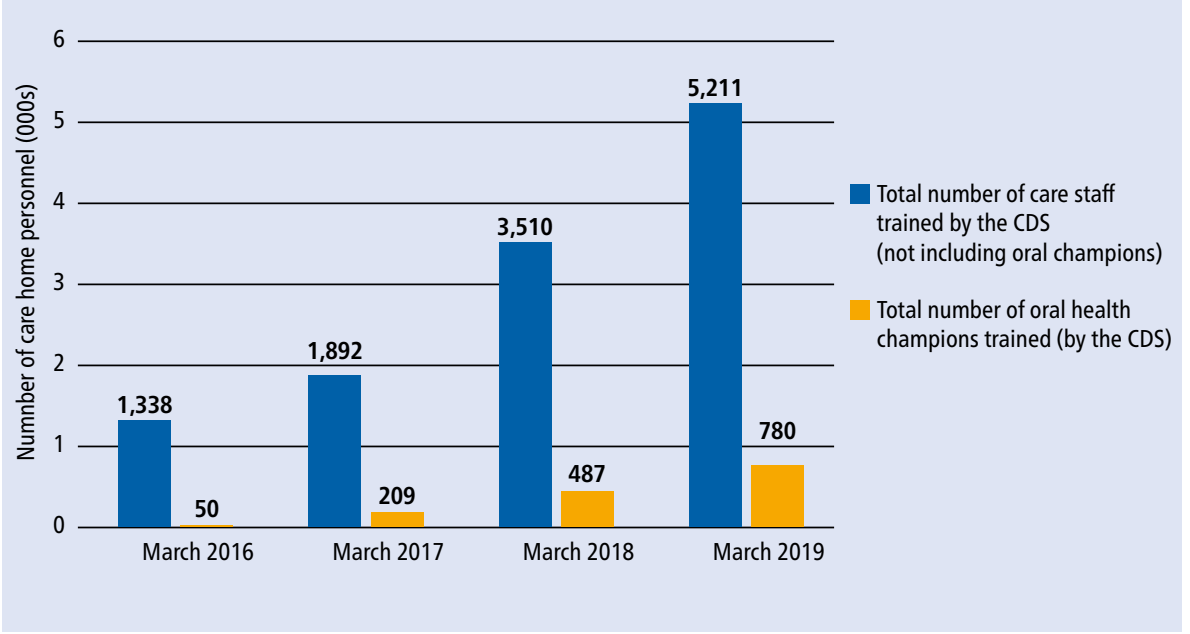

Fig. 4 Care home residents

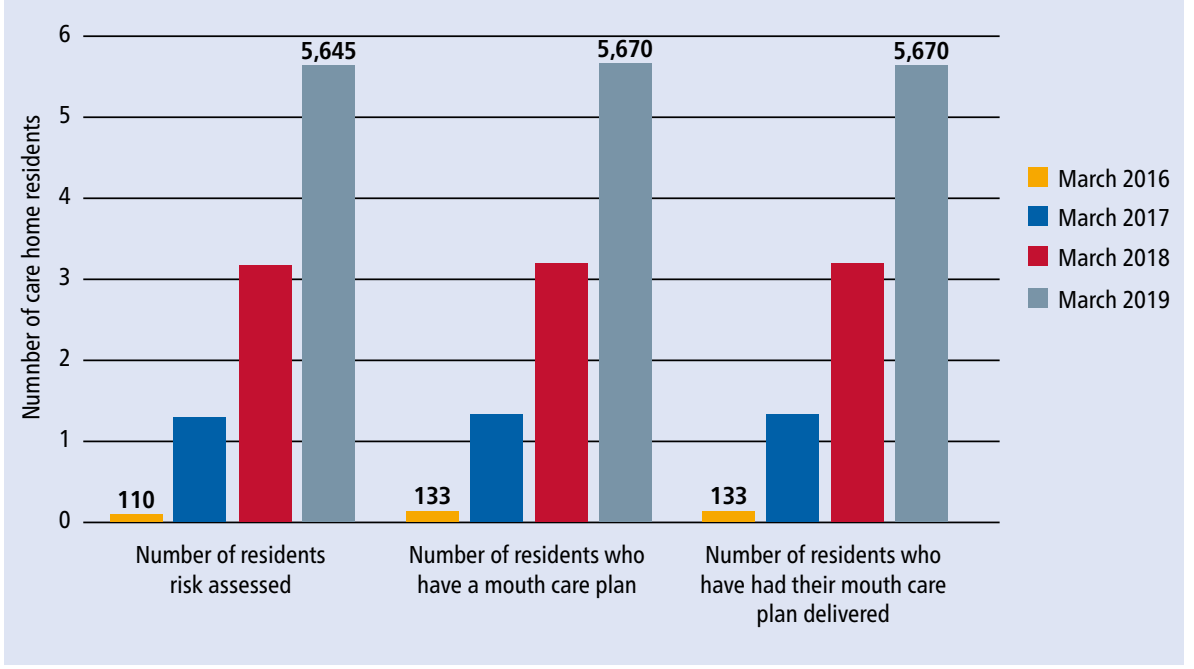

Table 2 Residents living in the homes participating fully

\begin{tabular}{l|l|l|l|l|l} 
Year & $\begin{array}{l}\text { Number } \\
\text { of homes }\end{array}$ & $\begin{array}{l}\text { Number } \\
\text { of } \\
\text { residents }\end{array}$ & $\begin{array}{l}\text { Residents } \\
\text { risk-assessed }\end{array}$ & $\begin{array}{l}\text { Residents who } \\
\text { have a mouth care } \\
\text { plan }\end{array}$ & $\begin{array}{l}\text { Residents who have } \\
\text { had their mouth } \\
\text { care plan delivered }\end{array}$ \\
\hline 2019 & 287 & 10,228 & 5,645 & 5,670 & 5,670 \\
\hline 2018 & 170 & 5,983 & 3,176 & 3,211 & 3,211 \\
\hline 2017 & 67 & 4,082 & 1308 & 1349 & 1349 \\
\hline 2016 & 17 & 3,723 & 110 & 133 & 133 \\
\hline
\end{tabular}

Gwên am Byth has used National Improvement Methodologies to good effect by starting small and ensuring improvement is incremental and embedded before spread takes place; this approach is reflected in the number of individual care home residents who are fully included in the programme at the time of reporting. Most importantly, the end users of the programme (the care homes) have driven its design, and their input and comments shaped the assessment and educational resources. The principle is that the programme is led by care home staff and supported by dental teams.

NICE's How to change practice ${ }^{24}$ identifies barriers within and beyond our control. Barriers can include: motivation; acceptance and beliefs; awareness and knowledge; lack of skills; and practical aspects. Gwên am Byth teams have encountered all of these in implementing the programme. Many have been overcome by: 
- Effective joint working with other health and social care professionals; for example, dietitians and pharmacists. The programme is also integrated into local oral health plans to facilitate joint working across health boards

- Sharing challenges, such as members of the CDS team contributing to the induction pack for new staff and to care home family/ carer days

- A willingness to be flexible-CDS personnel have listened to care home staff and actively engaged with them; for example, they introduced a care home staff mentoring scheme with accompanying 'buddy up' until staff members are confident to assess residents and deliver care.

In June 2019, the Care Quality Commission reviewed the state of oral healthcare in care homes across England. ${ }^{25}$ This highlighted an extensive lack of awareness of NICE guidelines and concluded that residents were not supported to maintain and improve their oral health. The British Association for the Study of Community Dentistry (BASCD) welcomed 'this important review which highlights the ongoing need for work to improve fundamental care and dignity for people living in care homes in England' and noted a real commitment to improving oral health for people in care homes from BASCD members who have been involved in the development of the programmes in Scotland and Wales. The British Society of Gerontology also welcomed the report and noted 'there are funded national programmes in Wales (Gwên am Byth) and Scotland (Caring for Smiles).'

In Wales, our experience is that care home staff training alone does not improve oral health, as evidenced by Welsh Fundamentals of Care audits. Therefore, Gwên am Byth incorporates the use of an assessment tool and care plans as well as staff training.

Although pre- and post-programme clinical oral assessment for residents has been considered, senior clinicians have advised of difficulties in conducting meaningful reviews of mouth cleanliness of frail older people who lack capacity.

Gwên am Byth focuses on oral hygiene in the care home but it needs to be complemented by dental care services for the pre-care home population. In Wales, the CDS and some GDPs provide services for older vulnerable adults who receive health and social care from other services in their own homes. These domiciliary

Fig. 5 Proposed model

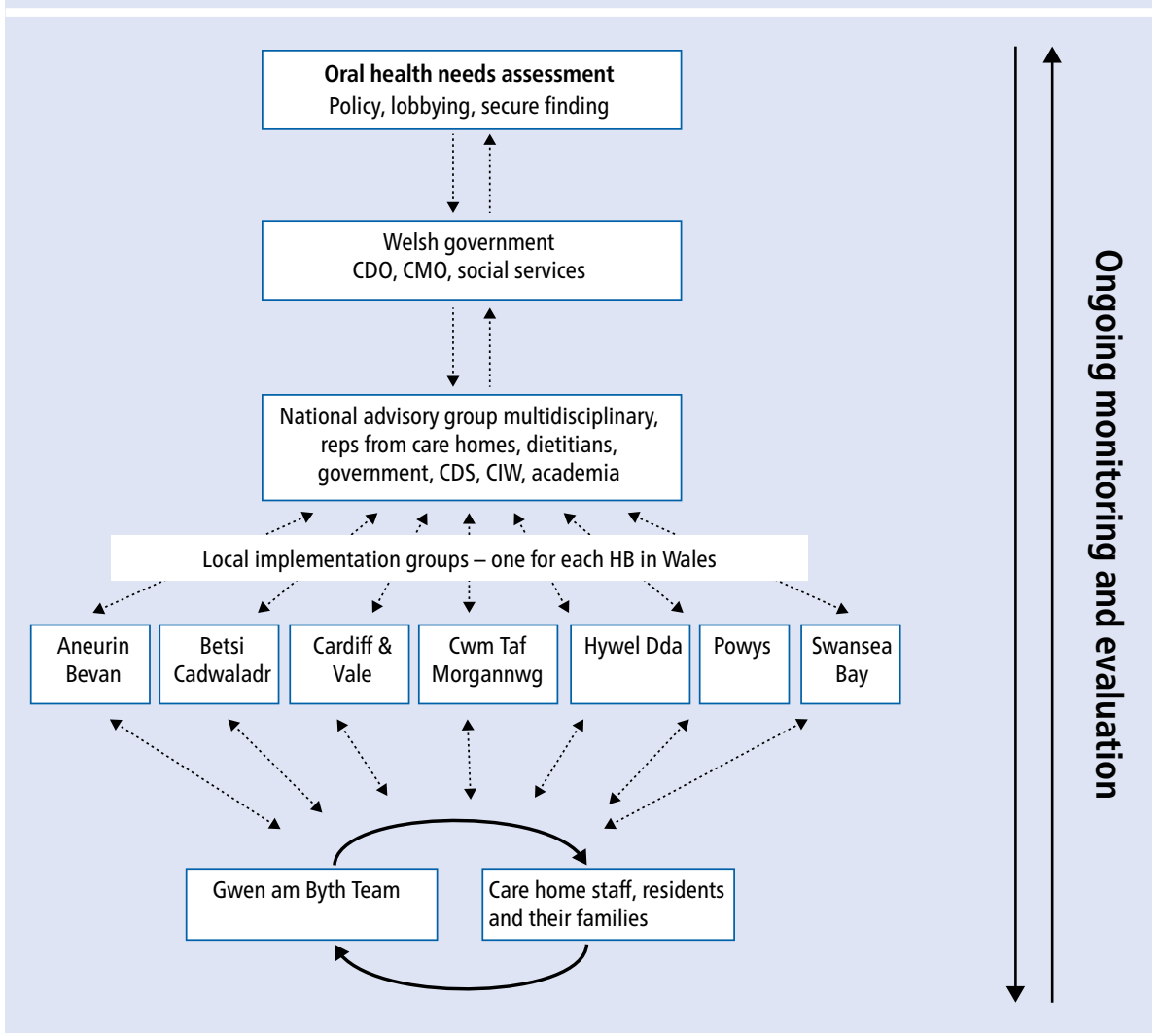

care staff are being invited to engage with the LIGs.

The authors would like to see another care home survey (similar to 2007) to further assess the outcomes of Gwên am Byth.

\section{Concluding remarks}

Starting with a blank page, a national programme has been established to improve the oral health of older people living in care homes in Wales. Our model of policy into action is illustrated in Figure 5 and highlights integrated working. In doing this, we have learnt several lessons:

- It takes time to translate policy into action; it's better to get it right than to rush the process

- Listen carefully to all stakeholders, respect their views and take them into account. There is common ground as all parties want to improve the oral health of residents, despite some differences in how that is achieved

- Engage care home staff and residents as the 'end users'; they will have their own perspectives, governance arrangements and evidence for improvement. It may be necessary to balance competing requirements to make progress
- Use the evidence base but also be pragmatic because delivery will rely on the local community and the skills they have

- Enlist government support and funding; support will be needed from both policymakers and those who can get things done - a balance between a strategic approach and action

- Dental team members may have to 'let go' and realise their role is to listen, learn and support, and not necessarily to deliver everything to do with oral health in the care home

- Value and recognise the commitment, skill and enthusiasm of the teams who are delivering the programme and the staff who make it happen in the care homes.

The Welsh Government has recognised the value of Gwên am Byth via its monitoring and evaluation by committing to double the recurrent funding commencing in early 2020 , in order to further contribute to dignified, person-centred and safe care of vulnerable older people living in Wales.

This paper was finalised during the COVID19 pandemic which further highlighted the need for good hygiene practice and effective training for all care home personnel who provide hands-on care to residents. 


\section{Acknowledgements}

The authors would like to acknowledge the input and support of: care home staff, residents and their families; the Clinical Directors of the CDS and the Gwên am Byth teams; the Chief Dental Officer for Wales; members of the Gwên am Byth National Advisory Group; Ilona Johnson, reader in dental public health; Claire Curtin, consultant in special care dentistry; and Nigel Monaghan, consultant in dental public health.

\section{References}

1. Monaghan N, Morgan M Z. Oral health policy and access to dentistry in care homes. J Disabil Oral Health 2010; 11: 61-68.

2. Karki A J, Monaghan N, Morgan M. Oral health status of older people living in care homes in Wales. Br Dent $J$ 2015; 219: 331-334.

3. Johnson I G, Morgan M Z, Monaghan N P, Karki A J Does dental disease presence equate to treatment need among care home residents? J Dent 2014; 42: 929-937.

4. Morgan M Z, Johnson I G, Hitchings E, Monaghan N P, Karki A J. Dentist skill and setting to address dental treatment needs of care home residents in Wales. Gerodontology 2016; 33: 461-469.

5. Monaghan N, Karki A, Playle R, Johnson I, Morgan $M$. Measuring oral health impact among care home residents in Wales. Community Dent Health 2016; 33: 1-5.

6. Office for National Statistics. Living longer: how our population is changing and why it matters. 2018. Available at https://www.ons. gov.uk/peoplepopulationandcommunity/ birthsdeathsandmarriages/ageing/articles/ livinglongerhowourpopulationischangingand whyitmatters/2018-08-13 (accessed May 2020).

7. Age UK. Later Life in the United Kingdom. 2019. Available at https://www.ageuk.org.uk/globalassets/ age-uk/documents/reports-and-publications/later life_uk_factsheet.pdf (accessed May 2020).
8. Health and Social Care Information Centre. Adult Dental Health Survey 2009 - Summary report and thematic series. 2011. Available online at https:// digital.nhs.uk/data-and-information/publications/ statistical/adult-dental-health-survey/adult-dentalhealth-survey-2009-summary-report-and-thematicseries (accessed February 2020).

9. Welsh Government. WHC/2015/001: Improving Oral Health for Older People Living in Care Homes in Wales. 2015. Available at https://gov.wales/sites/default/ files/publications/2019-07/improving-oral-healthfor-older-people-living-in-care-homes-in-wales.pdf (accessed October 2020).

10. Forder J, Fernandez J L. Length of stay in care homes - report commissioned by Bupa Care Services: PSSRU Discussion Paper 2769. 2011. Available at http:// eprints.Ise.ac.uk/33895/1/dp2769.pdf (accessed October 2020)

11. Welsh Local Government Association. Wales Market Analysis of Care Homes for Older people (draft findings for discussion). 2017. Available online at https://www. wlga.wales/introduction-to-market-analysis-of-carehomes-in-wales (accessed February 2020).

12. Smithard D G. Dysphagia: A Geriatric Giant? Med Clin Rev 2016; DOI: 10.21767/2471-299X.100014.

13. NICE. Oral health for adults in care homes: NICE guideline [NG48]. 2016. Available at https://www. nice.org.uk/guidance/ng48 (accessed February 2020).

14. Welsh Government. WHC/2016/028: Implications of the Social Services and Well-being (Wales) Act 2014 for Health Boards and NHS Trusts (updated as at April 2016). 2016. Available at http://www.wales.nhs. uk/sitesplus/documents/1064/WHC-2016-028\%20 Implications\%20of\%20the\%20Social\%20Services\%20 and $\% 20$ Well-being $\% 20 \% 28$ Wales $\% 29 \% 20$ Act $\% 20$ 2014.pdf (accessed February 2020).

15. Welsh Government and NHS Wales. Delivering Safe Care, Compassionate Care - Learning for Wales from The Report of the Mid Staffordshire NHS Foundation Trust Public Inquiry. 2013. Available at https://business.senedd.wales/documents/s18968/ Learning\%20for\%20Wales\%20fr (accessed February 2020).

16. Older People's Commissioner for Wales. A Place to Call Home?: Care Home Review Report. 2014. Available online at http://www.olderpeoplewales.com/en/news/ news/14-11-10/A Place to Call_Home_Care Home Review_Report.aspx\#.X5Igjlij7TIV (accessed February 2020).

17. NHS Wales. Health and Care Standards. 2015. Available online at http://www.wales.nhs.uk/governanceemanual/health-and-care-standards (accessed February 2020)

18. NHS Health Scotland. Caring for Smiles: Guide for Care Homes. 2013. Available at http:// www.knowledge.scot.nhs.uk/media/7460397/ caringforsmilescarehomes2013.pdf (accessed October 2020)

19. Jones R J, Johnson I G, Morgan M Z. Family and friends: Supporting oral care in care homes. Gerodontology 2019: 36: 258-266.

20. Welsh Government and Community Dental Teams in Wales, NHS Wales and 1000 Lives Improvement Wales. Gwên am Byth - a lasting smile: a resource to support safe and effective mouthcare for older people living in care home in Wales. Cardiff: Welsh Government, 2019

21. Letter from the Chief Medical Officer. Foam swabs - why they're banned in Wales. 2012. Available at http://www.1000livesplus.wales.nhs.uk/sitesplus/ documents $/ 1011 /$ Foam $\% 20$ swabs $\% 20-\% 20$ why $\% 20$ they\%27re\%20banned\%20in\%20Wales.pdf (accessed May 2020).

22. Slote Morris Z, Wooding S, Grant $G$. The answer is 17 years, what is the question: understanding time lags in translational research. J $R$ Soc Med 2011; 104: 510-520.

23. Dougall D, Lewis M, Ross S. Transformational change in health and care: Reports from the field. 2018. Available at https://www.kingsfund.org.uk/sites/default/ files/2018-05/Transformational_change_Kings_Fund_ May_2018_0.pdf (accessed February 2020).

24. NICE. How to change practice. 2007. Available at https://www.nice.org.uk/Media/Default/About/whatwe-do/Into-practice/Support-for-service-improvementand-audit/How-to-change-practice-barriers-to-change. pdf (accessed February 2020)

25. Care Quality Commission. Smiling Matters - Oral Health in Care Homes. 2019. Available at https://www.cqc.org. uk/sites/default/files/20190624_smiling matters full_report.pdf(accessed May 2020). 